\title{
A retenção dos alunos da Licenciatura em Química do IFCE, campus Quixadá: uma análise
}

\section{The retention of undergraduate students in Chemistry at IFCE, Quixadá campus: an analysis}

Resumo: O acesso ao Ensino Superior vem crescendo nos últimos anos, porém também aumentou os índices de retenção e evasão. A pesquisa baseou-se em um estudo de caso com uma abordagem qualitativa, com objetivo de identificar as principais fatores que influenciaram nas reprovações dos alunos, durante o primeiro ano, do curso de licenciatura em química do Instituto Federal do Ceará campus de Quixadá e por fim, propor ações a fim de minimizar o insucesso acadêmico na perspectiva dos alunos e professores, os semestres escolhidos para o estudo foram de 2017.2 e 2018.1. Os resultados mostraram as variáveis que mais contribuíram para as reprovações, como: falta de conhecimentos prévios e de identidade com o curso. As ações frente ao insucesso acadêmico propostas pelos professores e alunos foram parecidas, como oferta de cursos de nivelamento e a oferta regular de monitorias - medidas que o IES pode adotar para garantir o sucesso acadêmico.

Palavras-chave: Retenção. Evasão. Licenciatura em química.

Abstract: Access to higher education has been growing in recent years, but also increased retention and dropout rates. The research was based on a case study with a qualitative and quantitative approach, in order to identify the main factors that influenced students' failures, during

Ana Danielle de Queiroz

Melo

Doutora em Química Inorgânica. Professora do Instituto Federal de Educação Ciência e Tecnologia do Ceará (IFCE), campus Quixadá. Ceará, Brasil.

(iD) orcid.org/0000-0003-0995-4647

$\bowtie$ danielle.queiroz@ifce.edu.br

Sabrina Maria Cordeiro

Saldanha

Licenciada em Química pelo Instituto Federal de Educação Ciência e Tecnologia do Ceará (IFCE), campus Quixadá. Ceará, Brasil.

(iD) orcid.org/0000-0003-3370-5675

$\bowtie$ saabrinacs@gmail.com

Recebido em 14/04/2020 Aceito em 16/05/2020

Publicado em 20/05/2020

eISSN 2594-4002

doi $10.46551 /$ ees.e202005

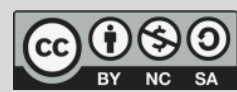
the first year, of the chemistry degree course at the Federal Institute of Ceará campus of Quixadá and finally, to propose actions in order to minimize academic failure from the perspective of students and teachers, the semesters chosen for the study were from 2017.2 and 2018.1. The results showed the variables that contributed to the failures, such as lack of prior knowledge and identity with the course. The actions in the face of academic failure proposed by teachers and students were similar, such as the offer of leveling courses and the regular offer of tutoring - measures that the HEI can adopt to guarantee academic success.

Keywords: Retention. Evasion. Chemistry graduation.

\section{Introdução}

O número de estudantes que têm ingressado no Ensino Superior nos últimos anos vem crescendo. De acordo com o Instituto Nacional de Estudos e Pesquisas Educacionais (INEP), em 2017 esse número teve um crescimento de 8,1\% em relação a 2016. No entanto, esse aumento acompanha a problemática da retenção escolar que se caracteriza pela maior 


\section{EdurañäsEscolakSociedade}

permanência do aluno no curso ocasionada dentre outros motivos pelas reprovações, o que também pode contribuir para o aumento no índice de evasão caracterizado pela desistência do curso. Esse fenômeno ocorre com maior frequência nos cursos com ênfase em formação de professores, ou seja, em licenciaturas (ARRIGO, SOUZA e BROIETTI, 2017). Estudos afirmam ainda que essa problemática pode ser explicada por fatores como as políticas educacionais, as condições de trabalho nas escolas, planos de carreira e as diversas dificuldades que um professor enfrenta no seu cotidiano, ou seja, o futuro docente pode desistir do curso não só por causa de problemas acadêmicos, mas, também, pelas adversidades na profissão.

A decisão do aluno em finalizar ou desistir do curso é uma questão que fomenta estudos que visam compreender os fatores que levam à permanência na graduação sob o ponto de vista do aluno. Segundo Tinto (2006), um especialista em análise sobre a retenção de alunos no Ensino Superior, a instituição de ensino possui uma parcela de culpa quando o aluno toma a decisão de evadir-se do curso. Logo, o aluno que possui a oportunidade de participar de projetos durante a graduação adquire um maior sentimento de pertencimento à instituição a qual está vinculado, por isso a importância de oferta de bolsas, auxílios e ações que promovam o engajamento dos alunos.

A presente pesquisa teve como objetivo identificar as principais variáveis que influenciaram reprovações no curso Licenciatura em Química do Instituto Federal de Educação, Ciência e Tecnologia, campus Quixadá, e propor ações a fim de minimizar o insucesso acadêmico. $\mathrm{Na}$ pesquisa, as disciplinas monitoradas foram escolhidas com base nos índices de reprovações; sendo assim, no $1^{\circ}$ semestre foram escolhidas as disciplinas de Fundamentos de Matemática e Química Geral I, e no $2^{\circ}$ semestre foram as disciplinas de Cálculo I e Química Geral II, tomando como base os semestre institucionais de 2017.2 e 2018.1. As disciplinas analisadas foram escolhidas a partir de dados extraídos do sistema acadêmico; esse sistema é responsável por reunir as informações sobre a vida acadêmica dos alunos no IFCE.

O Governo Federal propôs programas para facilitar o acesso ao Ensino Superior, mas ações que garantam a permanência e o sucesso do aluno no curso parecem não estar sendo eficientes. Diante disso, a Secretaria de Educação Profissional e Tecnológica (SETEC) recomendou a elaboração de um Plano Estratégico Institucional para Permanência e Êxito dos Estudantes às instituições da Rede Federal de Ensino (PPE) que, no âmbito do IFCE foi criado por meio da Resolução CONSUP n 67, de 31 de julho de 2017, sido implementando nesse mesmo ano com proposição de ações que deverão ocorrer no período 
de 2017 a 2024.

Desse modo, é de fundamental importância desenvolver estudos sobre a retenção escolar no Ensino Superior como forma de otimizar as ações do Plano de Permanecia e Êxito — conhecido pela sigla PPE. Por fim, viabilizar um diagnóstico e adoção de ações institucionais de caráter preventivo e visando minimizar e/ou eliminar as taxas que refletem o insucesso acadêmico.

\section{Retenção no Ensino Superior brasileiro}

Entende-se por retenção a situação que um aluno permanece no curso além do tempo máximo de integralização curricular (VASCONCELOS e SILVA, 2011; PEREIRA et al., 2014). Considera-se evasão escolar a saída do aluno do curso que pode ser explicada pela desmotivação, pelas dificuldades na compreensão dos conteúdos dentre outros. Para garantir a permanência e a qualidade da aprendizagem do aluno no âmbito escolar, o Brasil tem aplicado, há alguns anos, políticas públicas que possam cessar as taxas de reprovações (LAMERS, SANTOS e TOASSI, 2017). Essas ações, para ser eficientes, não podem ser aplicadas da mesma maneira em todos as IES, porque cada Instituição possui suas características próprias.

No Brasil, em 1995 iniciou-se um debate sobre a retenção e a evasão escolar a partir de um seminário sugerido pela Secretaria de Educação Superior do Ministério da Educação, organizado pela Comissão Especial de Estudos sobre a Evasão nas Universidades Públicas Brasileiras. O seminário teve como objetivo reunir um conjunto de dados sobre o desempenho das universidades públicas relacionado com as taxas de retenção, diplomação e evasão de estudantes nos seus cursos (BRASIL, 1997).

Para coletar os dados que possam explicar o alto índice de retenção, a Comissão Especial utilizou alguns métodos como o de Vincent Tinto, para quem os alunos que possuem menos envolvimento com o IES têm mais chances de desistir do curso (TINTO, 1975).

A criação do Planos de Reestruturação e Expansão das Universidades Federais (Reuni), em 2007, pelo Decreto $n^{\circ}$ 6.096, foi mais um estratégia do Governo Federal para melhorar o Ensino Superior a partir de metas a fim de proporcionar o acesso e permanência do aluno, medidas de redução ao índice de evasão, além de melhorar a estrutura física, ampliação de políticas de inclusão e assistência estudantil (BRASIL, 2007). 


\section{Edurañãa,Escola\&Sociedace}

Os alunos que concluem no tempo ideal representam aquele que realizou a trajetória idealizada pela instituição e serve como parâmetro de análise do sucesso acadêmico. O Brasil apresenta altos índice de retenção, entre o período de 2014 a 2016 houve uma queda no número de concludentes, esse fato pode ser explicado pelos índices como retenção, evasão e mobilidade dos estudantes entre as instituições e cursos, conforme dados do Instituto Nacional de Estudos e Pesquisas Educacionais Anísio Teixeira (BRASIL, 2017).

De acordo com Biazus (2004) para que possa minimizar as taxas de evasão nas IES, formas de prevenir o afastamento temporário ou definitivo do estudante devem ser implantadas. Em suas considerações,

o fenômeno evasão é maior do que a percepção que dele se tem; portanto, as Instituições devem reavaliar seus projetos políticos pedagógicos no sentido que as causas da evasão detectadas possam ser corrigidas com implantações de ações corretivas nos seus aspectos: curriculares; corpo docente - que tenham mais respeito, motivação, cuidado e profissionalismo para com os discentes (BIAZUS, 2004, P. 180).

Nesse sentido, Almeida e Soares (2004) salientam que o primeiro ano de graduação é considerado um período crítico, aumentando na vida estudantil os desafios ao longo da trajetória percorrida pelo universitário. Este problema enfrentado pelas universidades brasileiras, também é abordado em diversos países, mostrando que o afastamento dos alunos da graduação e as contínuas reprovações são acontecimentos complexos que constituem uma problemática educacional e social (VIDALES, 2009).

\section{O curso de Licenciatura em Química do IFCE, campus Quixadá}

O curso de Licenciatura em Química do Instituto Federal de Educação, Ciência e Tecnologia do Ceará (IFCE), campus Quixadá, iniciou suas atividades em 10 de junho de 2008, reconhecido pela Portaria n 688 do Ministério da Educação (MEC). O curso está organizado em três matrizes que se diferenciam pelo turno de funcionamento - diurno e noturno - e uma antiga e não padronizada; oferta cerca de 35 vagas semestralmente; a duração do período diurno é de 4 anos e o aluno pode estendê-la no máximo a 6 anos e meio, já o noturno tem duração de 4 anos e meio a 7 anos e meio no máximo (IFCE, 2018).

A ampliação de matrículas e a interiorização dos Institutos Federais, veio da preocupação do Estado com os locais desprovidos de políticas públicas de Educação Profissional e Tecnológica (TURMENA e AZEVEDO, 2017). Visando a democratização da 
Educação Superior no Brasil, o Governo Federal planejou estratégias como a criação do Reuni, em 2007, para melhorar o Ensino Superior por meio de metas a fim de proporcionar o acesso e permanência do aluno nas IES, medidas de redução ao índice de evasão, além de melhorar a estrutura física, ampliação de políticas de inclusão e assistência estudantil (BRASIL, 2007).

O IFCE atualmente conta com 35 campi, distribuídos em todas as regiões do Estado do Ceará. A sua ampliação veio pelo desenvolvimento de políticas educacionais a partir de 2008 (TURMENA e AZEVEDO, 2017). A escolha de cada curso por campus ocorre por consulta pública baseada nas necessidades da cidade sede.

O Projeto Pedagógico do Curso de Licenciatura em Química (IFCE, 2018) traz como um dos objetivos formar um profissional cidadão, ético, crítico-reflexivo, com conhecimento teórico e prático, e o compromisso nas transformações sociais, políticas e culturais. Conforme o Projeto,

\begin{abstract}
a unidade teoria/prática é o princípio fundamental que conduz as atividades orientadas por métodos ativos, como pesquisas, projetos, estudos de caso, seminários, visitas técnicas, práticas laboratoriais e de campo. Essa concepção decorre da necessidade de uma integração com o mundo do trabalho, resultante das inovações tecnológicas e científicas presentes na sociedade contemporânea. (IFCE, 2018, p. 2).
\end{abstract}

Cursos Superiores objetivam formar profissionais com competência para solucionar problemas no ensino, na pesquisa e na inovação, além de contribuir para o desenvolvimento de uma sociedade mais justa. Os cursos de licenciatura e programas especiais de formação pedagógica do IFCE têm em vista a formação de professores para a Educação Básica, principalmente nas áreas de Ciências Exatas, já que apresenta uma defasagem de professores licenciados (IFCE, 2009).

\title{
4 Metodologia
}

A pesquisa baseia-se em uma metodologia descritiva, tendo como personagens os acadêmicos do primeiro ano do curso de Licenciatura em Química e parte do corpo docente. A referida graduação é um dos cursos superiores ofertados pelo campus Quixadá do IFCE; possui duração de quatro anos e meio, na matriz noturna, e de quatro anos na matriz diurna, ambos na modalidade presencial. Por fim, também na forma presencial, a matriz antiga é estruturada em três anos e meio.

De abordagem qualitativa, a pesquisa foi dividida em duas etapas. $\mathrm{Na}$ primeira, 


\section{EdurañäsEscolakSociedade}

realizou-se uma coleta dos dados com o auxílio do sistema acadêmico, referente aos semestre de 2017.2 e 2018.1, sobre o rendimento referente a notas de aprovação, reprovação por falta e por nota, dos estudantes nas disciplinas de Fundamentos de Matemática, Química Geral I, Química Geral II e Cálculo I - disciplinas com os maiores índices de reprovação no primeiro ano do curso.

Logo após, realizou-se o contato com os principais personagens do processo de ensino e de aprendizagem, os professores e os alunos indicados pelo Sistema Acadêmico, que possui as informações acadêmicas dos alunos e sobre as disciplinas. Os alunos escolhidos foram aqueles que reprovaram pelo menos uma vez as disciplinas de Fundamentos de Matemática, Química Geral I, Química Geral II e Cálculo I durante os semestres de 2017.2 e 2018.1. Os cinco professores escolhidos foram os que lecionaram as disciplinas, nos semestres estudados, nomeados pelas letras A, B, C, D e E, a fim de manter a privacidade. A entrevista fundamentou-se em três perguntas norteadoras: existência de uma avaliação diagnóstica com as turmas; as variáveis que afetam o resultado na visão do professor; e a assiduidade dos alunos nas aulas. As entrevistas foram gravadas em áudios com duração que variou entre 3 a 10 minutos

Em seguida, foi aplicado um questionário aos alunos que ainda apresentavam matrículas ativas, composto por 15 perguntas, entre objetivas e subjetivas, que caracterizam o aluno por questões pessoais, vida escolar anterior, identidade com o curso, fatores sócio econômicos e o compromisso acadêmico. Ao todo, 41 alunos responderam o questionário, sendo 24 mulheres e 17 homens. O questionário aplicado teve como objetivo conhecer os alunos e a visão deles sobre os fatores que causam as reprovações.

Os dados foram analisados com o objetivo de identificar os possíveis fatores que influenciaram no insucesso dos alunos no primeiro ano de curso; o trabalho propôs algumas medidas que possam minimizar a reprovação e assim, a retenção. Para Silva, Rodrigues e Brito (2014) é de fundamental importância desenvolver ações que forneçam assistência ao aluno para permanecer e a concluir o curso com objetivo de melhorar o desempenho acadêmico e sua qualidade de vida.

\section{Resultados da pesquisa}

A pesquisa consistiu em identificar as variáveis que influenciaram nas reprovações dos alunos do curso de Licenciatura em Química, no primeiro ano do curso. Esse trabalho propõe ações estratégicas a fim de minimizar o insucesso acadêmico e garantir a continuidade 
do aluno no curso sem pendências, ou seja, a permanência da situação como aluno regular.

Os cinco professores que participaram da pesquisa foram convidados a responder as seguintes perguntas: É realizado uma avaliação diagnóstica dos alunos? Quais os principais fatores que afetaram o resultado? Como era a assiduidade dos alunos durante o semestre?

Os alunos responderam a um questionário. Do total de 59 alunos com histórico de reprovação, somente 41 foram encontrados e efetivamente participaram. Dos 18 restantes, 4 trocaram de curso, 7 trancaram, 5 abandonaram e 2 alunos, apesar de estarem matriculados em alguma(s) disciplina(s) no semestre em que foi realizada a pesquisa, apresentavam situação de abandono iminente, ainda não institucionalizado. A partir desses dados é possível analisar as quantidades de alunos que não conseguiram ou não possuem interesse em continuar no curso.

Os alunos sujeitos da pesquisa possuem faixa etária compreendida entre 18 a 36 anos. A maioria deles concluiu o Ensino Médio em escolas públicas estaduais, apenas 3\% responderam ter concluído em rede privada de ensino e nenhum dos pesquisados concluiu na rede federal. Ao serem questionados sobre o futuro profissional, 34\% não sabem se seguirão na carreira; $85 \%$ já pesaram em desistir do curso; $59 \%$ afirmam que pretendem trabalhar nessa área; e 7\% não querem atuar nessa área.

Os altos índices de reprovações em disciplinas do primeiro ano do curso mostram que os alunos enfrentam várias dificuldades, levando isso em consideração foi questionado se havia incômodo ao observar reprovações no histórico acadêmico, já que se trata de um documento importante. A insatisfação em ver uma reprovação, seja ocasionada por falta ou por nota, é de $85 \%$, os outros, $15 \%$, não se incomodam com o registro das reprovações no histórico. A preocupação com o histórico pode sugerir um maior comprometimento do aluno com o curso e assim possibilitando concluir com eficiência.

Entende-se que o primeiro ano de um curso de Ensino Superior é uma fase difícil de transição e adaptação, seja pela metodologia dos professores, pelo ritmo das atividades, pela própria estrutura de uma IES e pela identificação com o curso escolhido.

\subsection{As principais disciplinas que contribuíram para a retenção}

As disciplinas base dessa pesquisa foram selecionadas após a observação dos rendimentos dos alunos via sistema acadêmico que apontou as disciplinas de Fundamentos de Matemática e Química Geral I, integrantes do $1^{\circ}$ semestre, e Química Geral II e Cálculo 


\section{EdurañäsEscolakSociedade}

I, integrantes do $2^{\circ}$ semestre, como sendo as que apresentaram os maiores índices de reprovações. Historicamente, essas disciplinas ocupam esse posto e, por serem consideradas de nivelamento, refletem o déficit educacional.

Vale salientar que as disciplinas do primeiro semestre não podem ser trancadas, salvo exceções previstas no Regulamento da Organização Didática (ROD). Os alunos ingressantes que reprovaram em 2017.2, cursavam a disciplina novamente em 2018.1; com essa experiência facilita as chances de aprovação, o que explica a maior taxa de sucesso nas disciplinas do segundo semestre.

O Conselho Superior (CONSUP) do IFCE, o órgão máximo da instituição, apresenta caráter consultivo e deliberativo. Por meio de uma comissão formada por professores de todos os campi que ofertam a Licenciatura em Química, normalizou uma nova matriz curricular pela Resolução n. 47, de 22 de agosto de 2016. O campus Quixadá aderiu à essa normalização pela Resolução n. 30, de 13 de junho de 2016, tanto para os turnos de funcionamento diurno como noturno, ficando a critério do campus o turno de oferta.

No semestre de 2017.2 tomando como parâmetro a disciplina de Fundamentos de Matemática, apenas 30\% da turma conseguiu a aprovação, 35\% reprovaram por nota e 35\% por falta. No semestre de 2018.1, o índice de reprovação foi maior, sendo $62 \%$ por nota e

5\% por ausência. Quando comparada, houve aumento na taxa de aprovação no semestre de 2018.1, justificado pela maior assiduidade dos alunos. Porém, o número de reprovados por nota também aumentou, o que pode ser justificado pelo aumento do número de alunos na turma.

A disciplina de Cálculo I no semestre de 2017.2 foi ofertada no turno noturno para 19 alunos, desses $69 \%$ reprovaram - sendo $61 \%$ por falta e $8 \%$ por nota - e $31 \%$ conseguiram a aprovação. Em 2018.1, a disciplina foi ofertada no turno matutino com 12 matriculados, o número baixo de alunos pode ser explicado pelo elevado nível de reprovação em Fundamentos de Matemática, disciplina pré-requisito para Cálculo I.

Vale destacar que o total de alunos matriculados nas turmas de Cálculo I era de 19 em 2017.2 e de 12 alunos em 2018.1. No entanto, a pesquisa levou em consideração somente alunos da Licenciatura em Química, já que essa disciplina possui equivalência com outras disciplinas de Cálculo I, igualmente exigidas nos outros cursos superiores ofertados pelo campus, como Engenharia de Produção Civil e Engenharia Ambiental e Sanitária, disciplina essa que permite salas mistas com alunos de diferentes cursos.

Na disciplina Química Geral I, ofertada em 2017.2, tinham 32 alunos matriculados, 
desses 36\% aprovaram, 46\% reprovaram por nota e 18\%, por ausência. Para o semestre 2018.1, os índices de reprovação aumentaram, cerca de 55\% por nota e $12 \%$ por ausência. A disciplina Química Geral II apresenta como pré-requisito a Química Geral I, o que se espera um menor número de matriculados vinculados ao curso de Licenciatura em Química. De oferta noturna, em 2017.2, a turma era composta por 34 alunos, sendo que $70 \%$ da turma foi aprovada, $18 \%$ reprovaram por nota e $12 \%$ por ausência. No semestre 2018.1, a turma era composta por 10 alunos e foi ofertada no turno matutino; 57\% reprovaram por ausência, $29 \%$ por nota e apenas $14 \%$ conseguiram a aprovação.

Todos os dados apresentados anteriormente mostram o rendimento dos alunos nas quatros disciplinas com maiores índices de reprovações durante o primeiro ano do curso. Entende-se que esse período é uma fase de transição e adaptação, seja pela metodologia dos professores, com o ritmo de atividades, com a própria estrutura de uma IES e pela identificação com o próprio curso.

Com o resultado do questionário aplicado pode-se perceber que a maioria, 85\% dos pesquisados, já pensou em desistir do curso, o que pode denotar a desmotivação mais comum em alunos recém-ingressos.

\subsection{Possíveis fatores que ocasionaram nas reprovações}

Os fatores que influenciaram nas reprovações, na perspectiva dos professores entrevistados, foram déficit educacional, inexperiência com a calculadora científica, falta de identidade com o curso, muito conteúdo para ser ensinado em pouco tempo, falta de um planejamento de estudo por parte dos alunos e turmas lotadas.

A falta de conhecimentos prévios foi um dos fatores mais comentados pelos professores participantes. A seguir, as afirmações deles:

- Professor B — Infelizmente o que eu vejo é uma junção de duas coisas, primeiro realmente é a falta de base muitas vezes os alunos têm dificuldades em coisas básicas como as quatro operações matemáticas e interpretação de texto. O segundo fator é a questão de estar ali só por estar, muitas vezes não era a primeira opção de curso do ENEM.

- Professor C - O que afeta o resultado final, eu acredito que seja por questões de base, a formação inicial de entrada aqui ruim ou deficitária em matemática, essas ciências exatas acabam prejudicando um pouco. 
O segundo fator foi a inexperiência com a calculadora científica citado pelo o Professor A: "A maior parte que reprova possuem dificuldades muito grande tanto nas operações matemática e incluindo até o uso da calculadora científica, alguns erram na digitação e eu percebo no momento da correção da prova que na efetuação de uma conta para outra há erros, você percebe que são erros clássicos de digitação na calculadora".

Os professores afirmaram ser muito conteúdo para ensinar e a carga horária da disciplina é pequena frente ao conteúdo exigido nas ementas, como revela o professor A: "a carga horária da disciplina é muito curta para a quantidade de conteúdo que deve ser explicado", assim como fala o professor E: “tem um conteúdo grande para cumprir e o professor tem que fazer aquilo dá certo".

com o objetivo de conhecer e analisar a versão dos professores sobre a problemática de reprovações que podem causar a retenção e a evasão escolar, o Quadro 1 mostra os resultados obtidos na entrevista realizada com os cinco professores que lecionaram as disciplinas estudadas pela pesquisa nos semestre de 2017.2 e 2018.1. A entrevista foi baseada em três perguntas..

Quadro 1: Perguntas e respostas da entrevista com os docentes

\begin{tabular}{|c|c|c|c|}
\hline Participante & $\begin{array}{c}\text { Realizou uma prova } \\
\text { diagnóstica? }\end{array}$ & $\begin{array}{l}\text { A frequência dos } \\
\text { alunos era boa? }\end{array}$ & $\begin{array}{c}\text { Quais as variáveis que } \\
\text { influenciam o } \\
\text { resultado? }\end{array}$ \\
\hline Professor A & $\begin{array}{l}\text { Eu não realizei uma } \\
\text { prova diagnóstica com } \\
\text { eles. }\end{array}$ & $\begin{array}{l}\text { A frequência no começo } \\
\text { foi boa, mas à medida } \\
\text { que as provas vão } \\
\text { passando, eu costumo } \\
\text { fazer quatro provas, a } \\
\text { frequência vai } \\
\text { diminuindo. }\end{array}$ & $\begin{array}{l}\text { Turma com muitos } \\
\text { alunos é dificultoso. } \\
\text { Quando é uma turma de } \\
\text { vinte a vinte e cinto eu } \\
\text { acredito que seja o ideal, } \\
\text { mas entra outras } \\
\text { questões como de verba } \\
\text { e otimização de espaço. }\end{array}$ \\
\hline Professor B & $\begin{array}{l}\text { Na turma de } 2017.2 \text { na } \\
\text { química geral II não } \\
\text { realizei uma prova } \\
\text { diagnóstica, mas no } \\
\text { semestre de } 2018.1 \text { que } \\
\text { foi a disciplina de } \\
\text { química geral I eu } \\
\text { costumo realizar } \\
\text { dependendo do número } \\
\text { de aulas. }\end{array}$ & $\begin{array}{l}\text { A frequência dos alunos } \\
\text { que ficam é boa, que } \\
\text { começam e terminam } \\
\text { são bem assíduos, agora } \\
\text { realmente durante o } \\
\text { decorrer do curso muitos } \\
\text { vão desistindo, durante a } \\
\text { disciplinas muitos vão } \\
\text { evadindo. }\end{array}$ & $\begin{array}{l}\text { A falta de um horário de } \\
\text { estudo. Eles não querem } \\
\text { ser professores de } \\
\text { química e nem } \\
\text { químicos, então junta } \\
\text { essa questão da base } \\
\text { mais essa questão do } \\
\text { desinteresse pelo curso. }\end{array}$ \\
\hline
\end{tabular}




\begin{tabular}{|c|c|c|c|}
\hline Professor C & $\begin{array}{l}\text { Às vezes eu aplico um } \\
\text { teste inicial com } \\
\text { informações básicas, } \\
\text { teste escrito ou às vezes } \\
\text { argumentativo } \\
\text { perguntado em sala } \\
\text { mesmo. }\end{array}$ & $\begin{array}{l}\text { A frequência daqueles } \\
\text { alunos que realmente vão } \\
\text { permanecer é boa, que } \\
\text { gira em torno de } 50 \% \\
\text { após a N1. }\end{array}$ & $\begin{array}{c}\text { Um pouco de falta de } \\
\text { material como mais } \\
\text { livros disponíveis para } \\
\text { os alunos, porém esse é } \\
\text { um problema de vários } \\
\text { campi. }\end{array}$ \\
\hline Professor D & $\begin{array}{l}\text { Sim, na primeira } \\
\text { minha aula eu sempre } \\
\text { realizo uma avaliação } \\
\text { diagnóstica. }\end{array}$ & $\begin{array}{c}\text { A frequência não era } \\
\text { muito boa, por exemplo } \\
\text { no } 2017.2 \text { que foi a noite } \\
\text { eram vinte alunos em } \\
\text { meu diário, terminei o } \\
\text { curso com cinco ou seis, } \\
\text { se não me engano, e os } \\
\text { demais desistiram } \\
\text { mesmo. }\end{array}$ & $\begin{array}{l}\text { Tem monitor, mas eles } \\
\text { não procuram. }\end{array}$ \\
\hline Professor E & Eu não achei necessário. & $\begin{array}{c}\text { A frequência era muito } \\
\text { boa nas duas turmas. } \\
\text { Ambas começaram } \\
\text { grandes depois } \\
\text { diminuíram um pouco. } \\
\text { Nas turmas os alunos } \\
\text { ficavam atentos, mas } \\
\text { depois das primeiras } \\
\text { provas alguns se } \\
\text { desestimulam e desistem. }\end{array}$ & $\begin{array}{l}\text { O ônibus aqui que é } \\
\text { um problema um } \\
\text { pouquinho grave no } \\
\text { horário de chegada e } \\
\text { saída. Não tem um } \\
\text { livro oficial para a } \\
\text { disciplina, como não } \\
\text { tem um livro o aluno } \\
\text { tem que se virar e até a } \\
\text { gente para preparar } \\
\text { aula também. }\end{array}$ \\
\hline
\end{tabular}

Fonte: Dados da Pesquisa

Com base nesses dados, pode-se perceber a versão dos professores sobre os fatores que afetam o sucesso acadêmico dos alunos. Os cinco professores relataram que iniciam o conteúdo em um ritmo desacelerado, já que os alunos apresentam muitas dificuldades, como exemplo, nas operações matemáticas e interpretação de texto.

O diagnóstico se caracteriza como sendo uma avaliação aplicada nos primeiros dias de aula, com o objetivo de verificar o nível de aprendizagem do aluno sobre um determinado conteúdo. Não possui pontuação, pois como o próprio nome sugere, ela servirá de apoio para traçar estratégias de ensino respeitando o patamar de conhecimento da turma. A maioria dos professores entrevistados não aplica uma avaliação diagnóstica, no entanto, prefere realizar questionamentos breves durante as aulas a fim de avaliar os conhecimentos prévios de cada um.

Os horários das aulas foram distribuídos nos períodos matutino e noturno. O fato de as aulas serem no turno noturno, segundo os professores, não afetaram o resultado. Para esses, geralmente quem estuda à noite é quem trabalha, para quem o fator cansaço parece ser 


\section{Edurañăgessolar Saciedade}

o mais preponderante. Em geral, o número de alunos por turma não foi considerado um problema para os professores, porque apesar das salas começarem numerosas com o decorrer do semestre, muitos alunos desistem e assim a quantidade costuma diminuir drasticamente.

De acordo com os 41 alunos que participaram da pesquisa, os motivos que mais influenciaram nas reprovações foram: a falta de identidade; a metodologia empregada pelo professor regente; a falta de conhecimentos prévios; o desinteresse por não ter certeza se é a área que quer seguir; o acesso ao materiais didáticos pela oferta limitada de livros na biblioteca; as faltas nos horários das aulas; e a dificuldade no deslocamento até o campus.

A dificuldade no deslocamento até o campus foi um problema citado por $59 \%$ dos participantes, afetando diretamente a pontualidade e a assiduidade dos alunos nas aulas. $\mathrm{O}$ campus se localiza a uma distância de $5 \mathrm{~km}$ do centro da cidade de Quixadá. Por esse motivo, é de extrema importância um transporte de qualidade para locomover os alunos, além daqueles que não moram na cidade e que também necessitam de transportes particulares ou públicos para frequentar as aulas.

O Gráfico 1 mostra as porcentagens dos principais fatores que contribuíram para as reprovações.

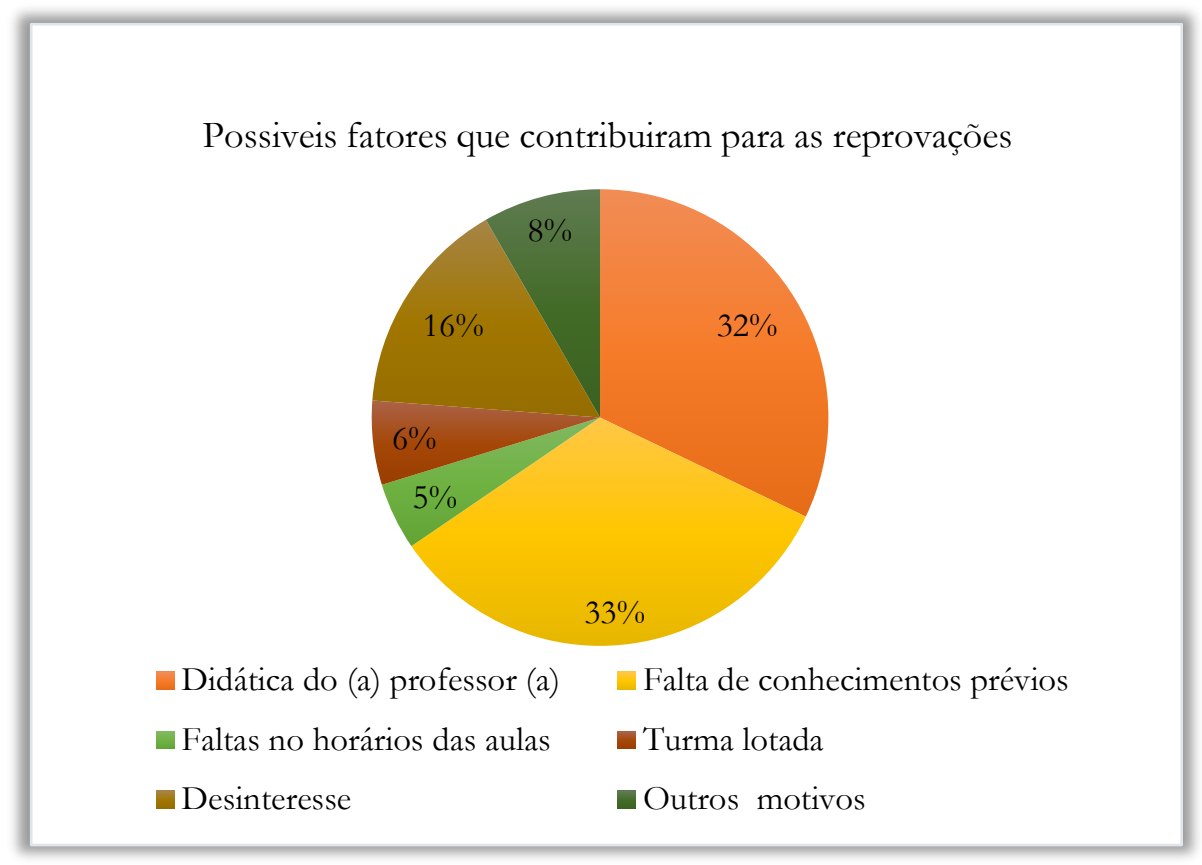

Gráfico 1: Fatores mais citados que contribuíram para as reprovações (Elaboração das Autoras)

A aplicação do questionário resultou na identificação dos principais fatores que contribuíram para as taxas de reprovação. Com 33\%, a maior porcentagem foi a falta de conhecimentos prévios, ou seja, a deficiência base e de um Ensino Médio de qualidade. A 


\section{Eduraçãa,EsodarSociedtade}

didática do professor foi o segundo fator apontado, com 32\%. O desinteresse apareceu com $16 \%$ e está relacionado geralmente com a não identificação do aluno com a graduação escolhida. Os fatores mais esquecidos foram a quantidade de alunos por turma e as faltas nos horários das aulas, $8 \%$ dos estudantes apontaram ainda outros fatores: atraso dos ônibus, excesso de disciplina por semestre e não ter tempo para estudar por conta do trabalho.

Após a identificação das principais variáveis que impactaram para as reprovações nas perspectivas dos professores e dos alunos, propõe-se as seguintes ações a fim de minimizar o insucesso acadêmico: ofertar cursos de nivelamentos no contra turno; promover uma formação em como utilizar a calculadora científica; estabelecer uma política de revezamento entre os professores que ministram as disciplinas ditas problemáticas; fornecer livros didáticos que embasarão a disciplina de nivelamento já institucionalizada, a de Fundamentos de Matemática; e, por fim, aplicar junto aos alunos uma formação sobre planejamento estratégico de estudos. As ações citadas anteriormente podem ser observadas no Gráfico 2.

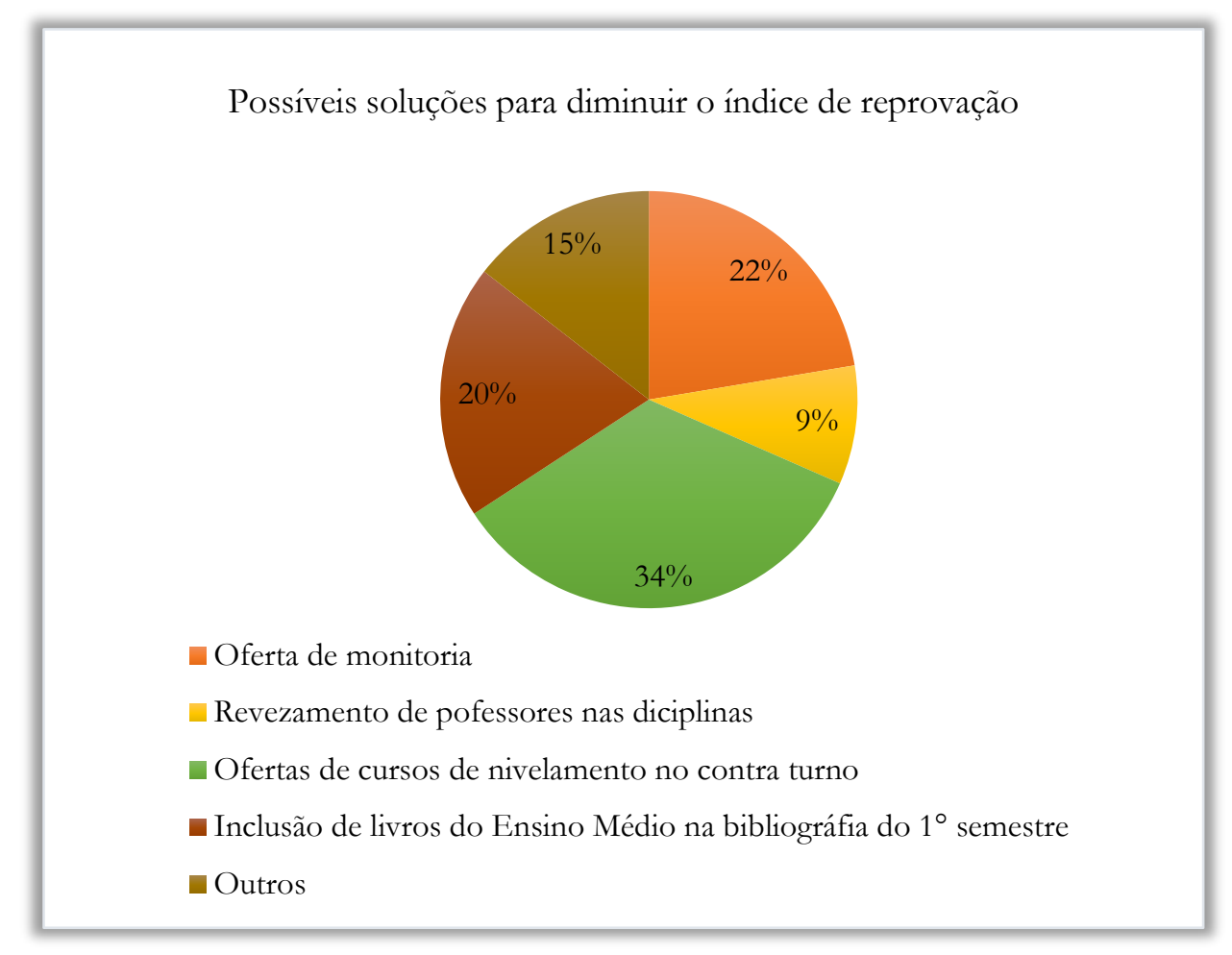

Gráfico 2: Possíveis ações para minimizar os índices de reprovações (Elaboração das Autoras)

As ações mais lembradas foram: a oferta de cursos de nivelamento com 34\%, a oferta de monitoria com $22 \%$ e com 20\%, a inclusão de livros do Ensino Médio. Outras possíveis ações apontadas foram diversificar os métodos avaliativos; ter mais aulas nos laboratórios; e promover com os alunos uma rotina de estudo fora da sala de aula. Com essas ações, os personagens do estudo sugerem uma diminuição nas taxas de reprovação. 


\section{Edurañãa,Escola\&Sociedace}

A inclusão de livro didático foi abordado pelos participantes como uma possível solução para diminuir e até cessar os altos índices de reprovação; a disciplina Fundamentos de Matemática não possui um livro didático especifico e isso prejudica o professor no seu planejamento de aula e, principalmente, os alunos que não possuem um material de apoio para seus estudos. Além disso, foi proposto a inclusão de livros do Ensino Médio para as disciplinas de Fundamentos de Matemática e Química Geral I já que esses livros possuem uma linguagem mais didática, facilitando aprendizagem dos alunos do primeiro semestre.

O livro didático possui um grande valor educacional e é uma ferramenta de caráter pedagógico habilitado a conduzir mudanças e melhorias na prática pedagógica, vale ressaltar que o livro não é um instrumento de informações prontas (SANTOS e MARTINS, 2011). A importância do livro nos processos de ensino e de aprendizagem é fundamental, pois possibilita uma orientação e um direcionamento do aluno com os conteúdos abordados nas disciplinas; para os professores, é um material de apoio durante as aulas.

Os recursos didáticos e a metodologia do professor auxiliam no processo de aprendizagem, além de ser de extrema importância para realizar um planejamento didático. O planejamento são ações que o professor vai realizar com seus alunos durante todo o período letivo; estabelece os métodos e os recursos que vão ser utilizados para facilitar a aprendizagem dos alunos, visando cumprir com os objetivos educacionais estabelecidos (MENDES, 2009).

As ações propostas por todos os participantes, professores e alunos, foram semelhantes e cabe ao campus ampliar a discussão a respeito das propostas levantadas a fim de garantir o sucesso acadêmico ao mesmo tempo que combatam a retenção/evasão.

\section{Considerações}

O IFCE, campus Quixadá, assim como em outras IES, enfrenta a problemática de altos níveis de retenção e da evasão escolar. A retenção é uma permanência prolongada do aluno, ocasionada por reprovações e que por vezes ocasiona seu abandono, medida em termos de evasão escolar. A pesquisa permitiu compreender a importância de um estudo que identifique os principais fatores que contribuem para as altas taxas de reprovação e, assim, planejar estratégias para minimizar o insucesso acadêmico.

Os sujeitos afirmaram que os fatores que mais influenciaram nas reprovações das disciplinas de Fundamentos de Matemática, Cálculo I, Química Geral I e Química Geral II, 
foram: a deficiência de base; o metodologia utilizada pelo professor que lecionou as disciplinas; a falta de identidade como curso; a falta de uma rotina de estudo fora da sala de aula; a inexperiência com a calculadora científica; a falta nos horários das aulas; a dificuldade no acesso dos materiais didáticos sugeridas pelos professores; a oferta limitada de livros pela biblioteca; e o deslocamento até o campus.

Ainda colaboraram sugerindo estratégias que possam solucionar a retenção escolar e que a IES pode adotar a fim de garantir o sucesso acadêmico. As ações propostas foram ofertar cursos de nivelamento no contra turno para aqueles estudantes que possuem deficiência "de base"; a inclusão de livros do Ensino Médio nas disciplinas de Fundamentos de Matemática e Química Geral I; realização de uma formação em como utilizar a calculadora científica com o auxílio de monitores; e oferta regular de monitorias.

Esse trabalho pode ser entendido como uma ação do Plano de Permanência e Êxito (PPE) ao mapear, identificar e avaliar as causas de retenção e consequente evasão e culmina, por fim em sugerir medidas de intervenção que contribuam para uma melhora na eficiência dos índices de sucesso acadêmico.

\section{Referências}

ALMEIDA, Leandro Soares; SOARES, Ana Paula. Os estudantes universitários desenvolvimento psicossocial. In: MERCURI, Elizabeth; POLYDORO, Soely Aparecida Jorge. (Org.). Estudante universitário: características e experiências de formação. Taubaté: Cabral Editora e Livraria, 2004, p. 15-40.

ARRIGO, Viviane; SOUZA, Miriam Cristina Covre; BROIETTI, Fabiele Cristiane Dias. Elementos caracterizadores de ingresso e evasão em um curso de Licenciatura em Química. ACTIO: Docência em Ciências, Paraná, v. 2, n. 1, p. 243-262, jan./abr. 2017.

BIAZUS, Cleber Augusto. Sistema de fatores que influenciam o aluno a evadir se dos cursos de graduação na UFSM e na UFSC: um estudo no curso de ciências contábeis. 2004. 203f. Tese (Doutorado em Engenharia de Produção) - Centro Tecnológico. Universidade Federal de Santa Catarina. Florianópolis.

BRASIL. Ministério da Educação. Secretaria de Ensino Superior. Diplomação, retenção e evasão nos cursos de graduação em instituições de Ensino Superior públicas. Brasília: MEC/SESu, 1997.

BRASIL. Ministério da Educação. Secretaria de Educação Superior. REUNI - Reestruturação e Expansão das Universidades Federais: Diretrizes Gerais. Brasília: MEC/SESu, 2007.

IFCE - Instituto Federal de Educação, Ciência e Tecnologia do Ceará. Estatuto. Fortaleza: IFCE, 2009.

IFCE - Instituto Federal de Educação, Ciência e Tecnologia do Ceará. Projeto Pedagógico Curricular de Química. Quixadá: IFCE, 2018. 


\section{Edurañăg,Escolad Sociedace}

BRASIL. Ministério da Educação. Instituto Nacional de Estudos e Pesquisas Educacionais Anísio Teixeira. Censo da Educação Superior - Notas Estatísticas 2017. Brasília: MEC/INEP, 2017.

LAMERS, Juliana Maciel de Souza; SANTOS, Bettina Steren dos; TOASSI, Ramona Fernanda Ceriotti. Retenção e evasão no Ensino Superior público: estudo de caso em um curso noturno e Odontologia. Educação em Revista, Belo Horizonte, v. 33, p. 1-26, abr. 2017.

MENDES, Sueli Ulian. O planejamento de ensino no trabalho do professor de $5^{a}$ a $8^{a}$ séries em uma escola pública de Tamarana: dificuldades e possibilidades. 2009. 62f. Trabalho de Conclusão de Curso (Graduação em Pedagogia) — Universidade Estadual de Londrina. Londrina.

PEREIRA, Alexandre Severino, CARNEIRO, Teresa Cristina Janes; BRASIL, Gutemberg Hespanha; CORASSA, Maria Auxiliadora de Carvalho. Perfil dos alunos retidos dos cursos de graduação presencial da Universidade Federal do Espírito Santo. In: XIV COLÓQUIO INTERNACIONAL DE GESTÃO UNIVERSITÁRIA, 2014, Florianópolis. Anais do XIV SIGU: a gestão do conhecimento e os novos modelos de universidade. Florianópolis, 2014, p. 1-16.

SANTOS, Vanessa dos Anjos; MARTINS, Liziane. A importância do livro didático. Candombá, Salvador, v. 7, n. 1, p. 20-33, jan./dez. 2011.

SILVA, Francisca Islandia Cardoso; RODRIGUES, Janete de Páscoa; BRITO, Ahélio Kleber Araújo. Retenção escolar no curso de Educação Física da Universidade Federal do Piauí. Educaşão em Perspectiva, Viçosa, v. 5, n. 2, p. 75-96, jul./dez. 2014.

TINTO, Vincent. Dropouts from higher education: a theoretical synthesis of recent research. Review of Rducation Research, Culumbia, v. 45, n .1, p 89-125, mar. 1975.

TINTO, Vincent. Research and practice of student retention: what is next? Journal of College Student Retention: Research, Theory \& Practice, v. 8, n. 1, p. 1-19, may 2006.

TURMENA, Leandro; AZEVEDO, Mário Luiz Neves. A expansão da Rede Federal de Educação Profissional, Científica e Tecnológica: os Institutos Federais em questão. Diálogo Educional, Curitiba, v. 17, n. 54, p. 1067-1084, jul./set. 2017.

VASCONCELOS, Ana Lúcia Fontes de Souza; SILVA, Márcia Nunes. Uma investigação sobre os fatores contribuintes na retenção dos alunos no curso de Ciências Contábeis em uma IFES: um desafio à gestão universitária. Registro Contábil, Alagoas, v. 2, n. 3, p. 21-34, set./dez. 2011.

VIDALES, Saúl. El fracaso escolar em la educación media superior: el caso del bachillerato de una universidad mexicana. Revista Iberoamericana sobre Calidad, Eficacia y Cambio en Educación, Madri, v. 7, n. 4, p. 320-341, set./dez. 2009. 